\title{
The Challenge of Nanovesicles for Selective Topical Delivery for Acne Treatment: Enhancing Absorption Whilst Avoiding Toxicity
}

This article was published in the following Dove Press journal: International Journal of Nanomedicine

\author{
Antonia Mancuso (D) \\ Maria Chiara Cristiano ${ }^{2}$ \\ Massimo Fresta (ID) \\ Donatella Paolino ${ }^{2}$ \\ 'Department of Health Sciences, \\ University "Magna Græcia” of Catanzaro, \\ Catanzaro 88100, Italy; ${ }^{2}$ Department of \\ Experimental and Clinical Medicine, \\ University "Magna Græcia” of Catanzaro, \\ Catanzaro 88100, Italy
}

\begin{abstract}
Acne is a common skin disease that affect over $80 \%$ of adolescents. It is characterized by inflammation of the hair bulb and the attached sebaceous gland. To date, many strategies have been used to treat acne as a function of the disease severity. However, common treatments for acne seem to show several side effects, from local irritation to more serious collateral effects. The use of topical vesicular carriers able to deliver active compounds is currently considered as an excellent approach in the treatment of different skin diseases. Many results in the literature have proven that drug delivery systems are useful in overcoming the toxicity induced by common drug therapies, while maintaining their therapeutic efficacy. Starting from these assumptions, the authors reviewed drug delivery systems already realized for the topical treatment of acne, with a focus on their limitations and advantages over conventional treatment strategies. Although their exact mechanism of permeation is not often completely clear, deformable vesicles seem to be the best solution for obtaining a specific delivery of drugs into the deeper skin layers, with consequent increased local action and minimized collateral effects.
\end{abstract}

Keywords: targeted therapy, skin, anti-acne drugs, nanocarriers, drug delivery systems

\section{Introduction}

Acne vulgaris is a common inflammatory pilosebaceous disease affecting over $80 \%$ of teenagers. It often persists into adulthood with a negative impact on the quality of life. The face is the most prone to acne skin lesions but the upper back, chest, neck and shoulders can also be affected, and scarring can last for life. ${ }^{1}$

The pilosebaceous follicle inflammation can result from several causes: 1) excessive sebum secretion from sebaceous glands, 2) hyperkeratinization and follicular plugging, 3) androgen-mediated effects, 4) inflammation and immunological host reactions, and 5) bacterial proliferation within the follicle. Propionibacterium acnes (P. acnes) plays an important role in the pathogenesis of acne because it induces inflammation through the stimulation of proinflammatory cytokines and inflammatory cells. ${ }^{2}$ Although these are accepted as the most common causes of acne, recent studies show that genetic factors could also be implicated in the onset of the pathology because they could enhance the activity of P. acnes. ${ }^{3}$

Other external factors, called "exposomes", such as nutrition, climatic factors, stress and different drug therapies, largely influence the incidence, duration and
Correspondence: Donatella Paolino University "Magna Græcia" of Catanzaro, Viale Europa, Catanzaro 88I00, Italy Tel +39096136942II

Email paolino@unicz.it
International Journal of Nanomedicine 2020:15 9197-9210 
severity of acne. In particular, different research groups have confirmed the correlation between acne vulgaris and psychological suffering, such as anxiety and depression., ${ }^{4,5}$ These factors act on the skin barrier and microbiota, influencing the course of the disease. ${ }^{3}$ The multifactoriality of the acne etiology highlights the need to treat the disease by an interdisciplinary approach; however, pharmacological therapy against $P$. acne remains the principal therapeutic approach.

Acne can be differentiated into three categories, as a function of its clinical manifestations: mild, moderate and severe. ${ }^{1}$ Mild acne generally involves the appearance of non-inflammatory comedonal lesions, few inflammatory papulopustular lesions, or both. In the case of moderate acne onset, more inflammatory lesions, occasional nodules or both appear. Finally, in severe acne, inflammatory lesions, nodules or both are common. The choice of treatment is generally related to the severity of the disease, and topical treatments are the first choice in mild and moderate acne because they generally have favorable safety profiles, while systemic therapies are preferred in severe and moderate cases. However, there is currently no definitive cure for acne. ${ }^{1,6}$

\section{Conventional Strategies for the Topical Treatment of Acne}

Owing to the complex etiopathogenesis of acne, as mentioned in the Introduction, different anti-acne drugs are used to treat the possible pathogenic factors. According to the new acne clinical guidelines of the American Academy of Dermatology, topical treatments based on benzoyl peroxide, retinoids or a combination of topical drugs including antibiotics are the first line treatment options for mild acne disease. ${ }^{7}$ Table 1 shows the main classes of drugs widely used in the topical treatment of acne, and some of the most common trademarks are also reported. Among these, retinoids present the best comedolytic activity, but they show a moderate anti-inflammatory and antibacterial efficacy., In contrast, antibiotics and benzoyl peroxide are mostly used for their antibacterial and anti-inflammatory properties. ${ }^{8}$ Topical dapsone $5 \%$ gel and azelaic acid have also been recommended for inflammatory acne and post-inflammatory dyspigmentation, respectively. ${ }^{7}$

Although topical acne treatment is safer than systemic therapies, and therefore it is considered as first-line therapy for mild and moderate acne, there are both advantages and disadvantages of topical use. First of all, the

Table I Examples of the Most Commonly Prescribed Topical Acne Treatments

\begin{tabular}{|c|c|c|c|}
\hline Molecule & Trademarks & $\begin{array}{l}\text { Pharmaceutical } \\
\text { Class }\end{array}$ & Side Effects \\
\hline Benzoyl peroxide & Benzac $^{\circledR}$ Clean Gel; Panoxy $\left.\right|^{\circledR}$ & Antimicrobial & $\begin{array}{l}\text { Redness, desquamation, bleaches hair and } \\
\text { clothes }\end{array}$ \\
\hline Clindamycin & $\begin{array}{l}\text { Dalacin-T }{ }^{\circledR} ; \text { Zindaclin }^{\circledR} \operatorname{Treclin}^{\circledR} \text { (combined } \\
\text { with tretinoin) }\end{array}$ & Antibiotic & $\begin{array}{l}\text { Resistance overgrowth of Gram-negative } \\
\text { bacteria, irritation, itching }\end{array}$ \\
\hline Erythromycin & $\begin{array}{l}\text { Eryacne }^{\circledR} \text { Zineryt }^{\circledR} \text { (combined with zinc } \\
\text { acetate) }\end{array}$ & Antibiotic & $\begin{array}{l}\text { Resistance and overgrowth of Gram-negative } \\
\text { bacteria }\end{array}$ \\
\hline $\begin{array}{l}\text { Clindamycin + benzoyl } \\
\text { peroxide }\end{array}$ & BenzaClin ${ }^{\circledR}$; Duac ${ }^{\circledR}$ Acanya ${ }^{\circledR}$ & $\begin{array}{l}\text { Antibiotic }+ \\
\text { Antimicrobial }\end{array}$ & Resistance, redness, desquamation \\
\hline $\begin{array}{l}\text { Erythromycin + benzoyl } \\
\text { peroxide }\end{array}$ & Benzamycin $^{\text {TM }}$ & $\begin{array}{l}\text { Antibiotic }+ \\
\text { Antimicrobial }\end{array}$ & Resistance, redness, desquamation \\
\hline Dapsone & Aczone $^{\circledR}$ & $\begin{array}{l}\text { Antibiotic/ } \\
\text { anti-inflammatory }\end{array}$ & Dryness, erythema \\
\hline Azelaic acid & Finacea $^{\circledR}$ & Antimicrobial & Burning, stinging and tightness of the skin \\
\hline Tretinoin & Avita $^{\circledR}$; Retin-A ${ }^{\circledR}$, Ketrel $^{\circledR}$ & Retinoid & Erythema, scaling, burning, flare \\
\hline Terazotene & Zorac $^{\circledR}$ & Retinoid & Erythema, scaling, burning, flare \\
\hline Adapalene & $\begin{array}{l}\text { Differin }^{\circledR}, \text { Tactuo }^{\mathrm{TM}}, \text { Epiduo }^{\mathrm{TM}} \text { (combined } \\
\text { with benzoyl peroxide) }\end{array}$ & Retinoid & Irritation, erythema, peeling, dryness \\
\hline
\end{tabular}


application of topical drugs is not free from side effects. The most common cutaneous manifestations are local skin irritation, which looks like erythema, dryness or scaling; in the case of benzoyl peroxide and topical retinoids, the worst irritating effects are shown, and sometimes this leads to the patient discontinuing therapy. ${ }^{10}$ Moreover, the use of topical retinoids such as adapalene, terazotene or tretinoin could lead to several collateral effects in pregnancy, so they should be used very carefully in women with childbearing potential. On the other hand, benzoyl peroxide shows advantages owing to its oxidative mechanism, it reduces anaerobic bacteria and is rapidly reduced to benzoic acid, so it is considered safe for use in pregnant or lactating women. Another advantage of treatment with benzoyl peroxide is that it does not confer $P$. acnes resistance. However, the anti-oxidative defense of the stratum corneum could be compromised by the potent oxidative stress inflicted by the drug. The loss of vitamin $\mathrm{E}$ from the epidermal barrier was also reported and could represent a limit of its topical use as a free drug. ${ }^{11,12}$ These reactions can cause side effects (desquamation, burning or redness) on skin barriers. It is noteworthy that the combination of benzoyl peroxide with tretinoin or adapalene showed an increased activity but, at the same time, increased collateral effects were also reported. ${ }^{13}$

Dryness and burning are less common side effects for topical antibiotics, while drug resistance may occur following a longer treatment with topical antibiotics. In particular, their use in monotherapy can lead to P. acnes resistance phenomena, and the overgrowth of the resistant skin flora Gram-negative microorganisms can evolve in a Gram-negative folliculitis, worsening the pathological condition of the patient. So, the association of different topical antibiotics or the combination of antibiotics and benzoyl peroxide is often required. ${ }^{9,10}$ These associations show an increased efficacy, probably because the efficacy against the microbial component is improved by the enhanced permeation of the antibiotic due to the keratolytic effect of the benzoyl peroxide. ${ }^{14}$

Azelaic acid is another drug commonly used for acne treatment. It seems to be active in the reduction of bacteria also showing anti-inflammatory effects. ${ }^{15}$ The administration of azelaic acid is considered safe in pregnancy. Although it may lead to topical effects such as burning and tightness, it is safe in pregnant and lactating females because it is a natural compound generally present on the skin, so it normally does not causes systemic side effects. ${ }^{13}$

Other topical and increasingly conventional treatments proposed for acne treatment include light therapy and photodynamic therapy. ${ }^{16}$ These strategies have shown effectiveness in destroying sebaceous glands and killing $P$. acnes. Individuals with inflammatory acne exhibited beneficial effects if treated with these procedural therapies based on photosensitizers and a light source. However, some data have shown that patients occasionally present with local blisters and pain, and therefore further studies are necessary to prove the safety of this treatment. ${ }^{6}$

Despite the proven efficacy of topical treatments, none of the most frequently prescribed anti-acne drugs are free from side effects. Not only are collateral effects due to the dose of drug administered, but they also seem to be related to the type of formulation used. ${ }^{13}$

\section{Topical Drug Delivery Systems to Overcome the Limits of Conventional Therapies}

In addition to the several side effects which can occur following a topical administration of anti-acne drugs, an important limitation is the inability of many drugs in free form to cross the stratum corneum.

The stratum corneum represents the main skin barrier, and it reduces the efficacy of the topical treatment of different diseases, hindering drug permeation through the skin. ${ }^{17}$ Over the past decade, nanomedicine and particularly topical drug delivery systems have been the focus of interest of different research groups because of their ability to overcome the limits of the skin barrier without altering the physiological and functional features. Moreover, they provide good therapeutic efficacy of the carried drug, increasing its local efficacy and also minimizing its side effects. ${ }^{18}$ Several studies in the literature have demonstrated the improvement in efficacy of topical drug delivery systems in the treatment of different skin diseases compared to the marketed formulation (Figure 1) or a solution of the free drug. ${ }^{19-21}$ The safety of topical treatment of the most common lipid-based nanocarriers, including niosomes, ethosomes $^{\circledR}$ (etho) or transfersomes ${ }^{\circledR}$ (ultradeformable vesicles), has been investigated and they have been demonstrated to cause only rapidly reversible alterations of the stratum corneum. In one study, transepidermal water loss (TEWL), the main indicator of skin barrier integrity, was monitored in vitro after the topical application of niosomes, 


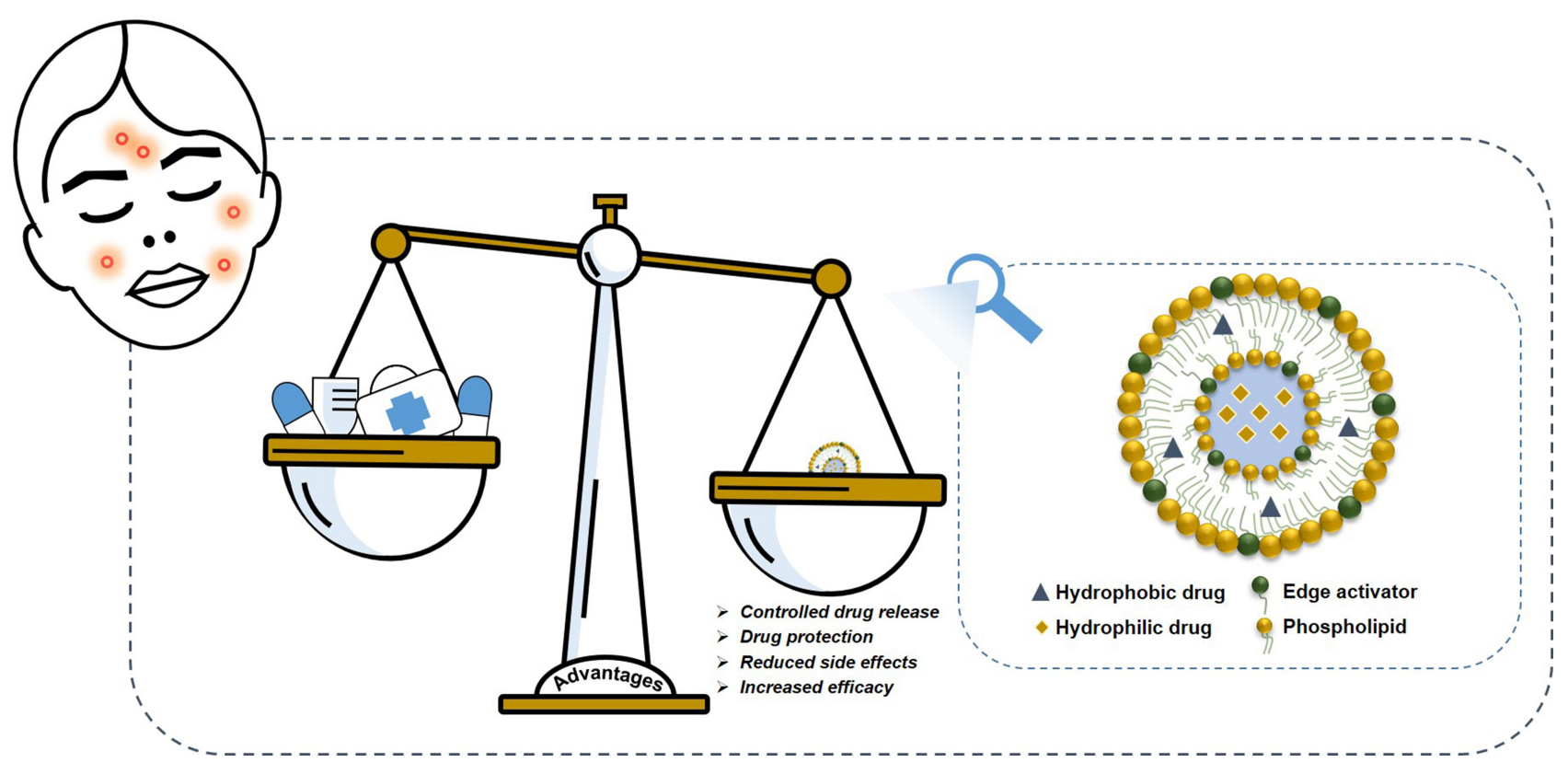

Figure I Schematic representation of the advantages of nanomedicine in acne treatment compared to conventional therapies.

etho and ultradeformable vesicles, and an initial alteration of values was observed, owing to the interaction between carrier and membrane, but the native TEWL values were restored soon afterward, within 72 hours of incubation. The study showed that an initial interaction between carriers and skin structures occurred to allow the topical delivery of drugs, but without inducing irreversible modifications. ${ }^{22}$ The carriers analyzed in that study are among the most used drug delivery systems involved in the treatment of acne disease.
In detail, Figure 2 summarizes the liposomes and liposomallike vesicles that have been studied to date for the topical treatment of acne and which will be broadly covered in this review.

\section{Liposomes}

Liposomes are spherical vesicles, characterized by a phospholipid bilayer and an aqueous core. Although these carriers are not generally able to reach the deeper

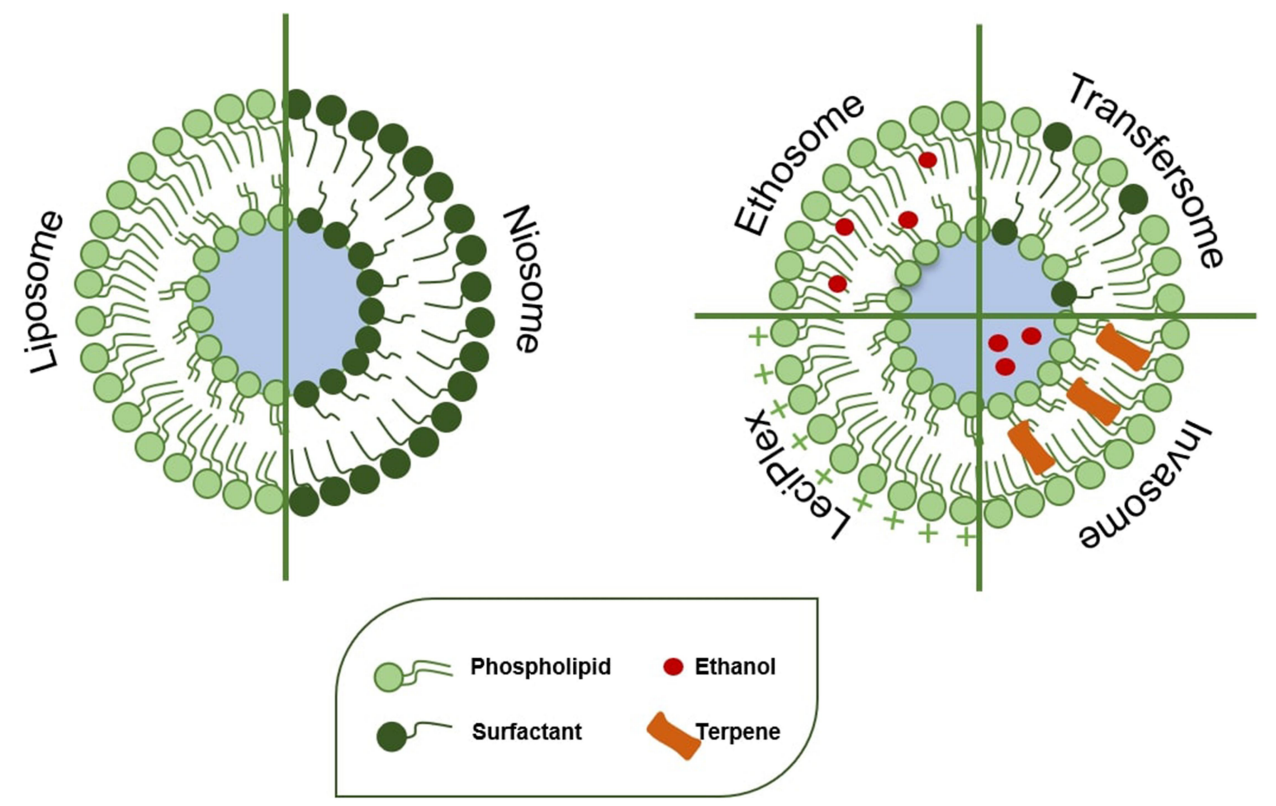

Figure 2 Schematic representation of liposomes and liposomal-like vesicles. 
skin layers, as they are not created as topical drug delivery systems, this allows the delivered drugs to accumulate at the administration site. ${ }^{23}$ For this reason, their efficacy has been shown in topical treatment of several diseases, and clinical trials have also been performed using anti-acne drugs encapsulated into liposomes. ${ }^{24-26}$ The physicochemical characteristics have proved to be very important for defining the permeating and releasing abilities of liposomes. In fact, the bilayer can exist in a solid-ordered phase or in a fluid-disordered phase as a function of the employed phospholipids and temperature, as this structural difference could be exploited to trigger the release of the active ingredients. ${ }^{27}$ Comparison studies between different liposomal formulations demonstrated that hydrogenated soya lecithin/cholesterol types presented the best penetration abilities through the skin, while liposomes containing non-ionic emulsifiers such as alkyl tetraglycol ethero-phosphoric acid esters or fatty alcohol polyglycol ether in their structures showed better release abilities than lecithin-based types. However, both of the liposomal systems loaded with the antibiotic clindamycin showed improved efficacy in anti-acne clinical studies compared with the free clindamycin lotion. ${ }^{28}$ No less important are the in vivo results described by the authors: the patients treated with clindamycin-loaded liposomes showed a significant decrease in lesions after 4 weeks of treatment. Moreover, no side effects were shown compared to the treatment using the free form of drugs, probably thanks to modulated drug release in terms of time and site.

Dipalmitoyl phosphatidylcholine (DPPC), included in the liposomal formulation, was shown to induce an increased skin deposition of retinoic acid-loaded liposomes $(41 \%$ and $13 \%$ into the epidermis and dermis, respectively) compared to its alcoholic gel (18\% and $8 \%$ into the epidermis and dermis, respectively); this study highlighted that the liposomal formulation is able to reduce the systemic effects of drug and to improve the local effect of tretinoin in the skin. ${ }^{29}$ Further in vitro studies confirmed the same ratio in skin accumulation with higher registered values $(65.7 \%$ and $33.6 \%$ for liposome and gel, respectively). ${ }^{29,30}$

The influence of the surface charge, closely related to the liposomal composition, was also investigated in different studies to clarify its role in topical drug delivery.

This is the case for retinoic acid-loaded positively charged liposomes. Shah et al demonstrated that their positively charged liposomes penetrated into excised pig ear skin more than 3.7-fold compared to the neutral vesicles. ${ }^{31}$ In another study, Jung et al confirmed this trend, ${ }^{32}$ demonstrating that the positively charged and amphoteric liposomes permeated skin more effectively through the transfollicular route, compared to negatively charged vesicles. These data disagree with a more common idea that negatively charged vesicles are more able to cross the skin, because the interaction between opposite charges could otherwise limit the permeation. An ionexchange interaction between the cationic vesicles and negative charges of the skin and hair follicle is probably established, but more studies need to be performed to clarify how this interaction could promote the penetration of nanosystems or influence the surface accumulation. The importance of the liposome composition in skin delivery has been demonstrated by Rahman et al. A tretinoinloaded liposomal formulation made up of 9:1:0.01 phospholipid-cholesterol-dicetylphosphate was proven to be superior to the marketed product in terms of higher efficacy against non-inflammatory lesions and lower skin irritation phenomena following administration. ${ }^{33}$ These advantages of the liposomal formulation are related to its composition. The cholesterol was able to reduce vesicle sizes in order to control skin permeation and deposition, while dicetylphosphate significantly enhanced drug release. ${ }^{33}$ A tretinoin-loaded liposomal formulation was studied by Eroğlu et al. ${ }^{34}$ They found that drug-loaded liposomes permeated the skin more effectively and were not easily removed from the site of action, compared to conventional gel. Moreover, an increased skin tolerability and patient compliance was shown, and this was due to the drug being protected from exposure to the destabilizing oxygen, light and acids. The commercial gel was more effective than the liposomal formulation. Based on these assumptions and to improve the efficacy of the formulation, the authors prepared a multidrug formulation. Tetracycline $\mathrm{HCl}$ and tretinoin were contained in a carbopol-based liposomal gel in order to exploit the comedolytic and bacteriostatic synergistic effect. The obtained multidrug formulation showed good technological characteristics in terms of acceptable adhesiveness and viscosity, $\mathrm{pH}$, and controlled and biphasic release of the two drugs. Finally, the antibacterial efficacy of the formulation has been proven against Staphylococcus aureus and Streptococcus epidermidis, and the same minimal biofilm eradication concentration was found when compared to the conventional gel containing the two drugs. However, the liposomal gel formulation containing the two drugs showed lower minimum inhibitory concentration (MIC) 
values against Staphylococcus aureus compared to each solution of the single drug. ${ }^{34}$

Another combination therapy, associating retinoic acid $(0.025 \%)$ with benzoyl peroxide $(2.5 \%)$ in liposomal gel, was investigated in clinical studies on acne patients; it led to the disappearance of skin lesions within 10 weeks, showing greater efficacy than the gel with the two free drugs. $^{35}$

Focusing on benzoyl peroxide, its encapsulation in a liposomal formulation led to a significant improvement of drug efficacy against Propionibacteria and Micrococcaceae compared to the other pharmacopoeia benzoyl peroxide formulations. ${ }^{30,36}$ So, benzoyl peroxideloaded liposomes seem to be advantageous both as a monotherapy and as a multidrug association.

The ability of liposomes to protect their content drug from external agents, such as light and oxygen, has allowed evaluation of the use of essential oils in the treatment of acne, also increasing their solubilization ${ }^{37}$ and reducing their irritating effect on the skin. ${ }^{34,37,38}$ Interest in the biological activity of essential oils for the treatment of topical skin diseases is increasing. Many researchers have already demonstrated the ability of essential oils in the treatment of skin diseases. Essential oils such as tea tree oil, cinnamon oil and rosemary essential oil showed activity against Propionibacterium acne and Staphylococcus epidermis. ${ }^{39}$ Essential oil-loaded liposomal formulations have also been investigated, and it was demonstrated that the loading of essential oils decreases the mean size of liposomes because they are able to increase the cohesion packing among the apolar chains in the bilayer. ${ }^{40}$ Moreover, it was observed that monoterpenes contained in the essential oils are located at the polar head group region of the bilayer, causing an increase in the vesicle surface curvature and so determining a further decrease in the mean size. ${ }^{41}$

Tea tree oil was encapsulated into liposomes to enhance the follicular delivery of this antimicrobial agent. Tea tree oil-loaded liposomes were formulated, and the cyanoacrylate method was used to evaluate the follicular uptake of vesicles, demonstrating a better targeting ability compared to the other analyzed formulations, microemulsion, multiple emulsion and colloidal bed. ${ }^{42}$ Liposomal encapsulation of essential oils preserved the stability and increased the solubility of encapsulated essential oil, and at the same time essential oils were able to decrease the liposomal size, enhance the fluidity and control the oxidation of the lipid bilayer. ${ }^{43}$

\section{Niosomes}

Similarly to liposomes, niosomes are characterized by a highly ordered bilayer and an aqueous core, but in this case the bilayer is made up of non-ionic surfactants (for example, cetyl alcohol, decyl glucoside, Brij, polysorbates, spans and poloxamers). ${ }^{44}$ In some cases, niosomes are preferred as carriers over liposomes because they are able to overcome the problems related to the purity of phospholipids and they also show higher vesicle stability, owing to their greater resistance to lipid peroxidation which, in contrast, makes the liposomes unstable over time. $^{45}$ They have excellent biocompatibility, low toxicity and low preparation costs. ${ }^{46}$

The chemical components of vesicles determine their peculiarities. The non-ionic surfactants that represent the building blocks of the structure can act as permeation enhancers, improving the skin delivery of the encapsulated drug. They probably fuse with the skin surface, enhancing the permeation of drugs through the stratum corneum, owing to their ability to temporarily modify the structure of this barrier. ${ }^{22,47}$

Because of their apparent advantages, especially in terms of carrier non-toxicity, the potential of niosomes in the treatment of skin diseases, such as acne, was investigated. A comparison study between retinoic acid-loaded liposomes and niosomes was performed to investigate the influence of nanovesicle composition on their cutaneous delivery ability. The study by Manconi et al showed that niosomes penetrate the skin more effectively. ${ }^{48}$ The authors investigated the potential of niosomes to control the cutaneous delivery of tretinoin. They performed permeation studies using newborn pig skin interposed between donor and receptor compartments of Franz diffusion cells, and concluded that topical drug delivery was strongly affected by the vesicle structure, size and charge (obtained using stearylamine or dicetylphosphate as a charge inducer) and by the thermodynamic activity of the carried drug. The authors attributed the good skin-penetrative ability of niosomes to their composition, and in particular to the presence of alkyl polyglucosides (APG), a class of non-ionic surfactants. Moreover, small negatively charged niosomes, saturated with tretinoin, showed a greater cutaneous retention of drug compared to positively charged vesicles, which, in contrast, could permeate more effectively. Liposomes and the commercial preparation Retin $A^{\circledR}$ (Janssen-Cilag, Milan, Italy) showed a lower retention compared to negatively charged niosomes, but the trend was not the same when 
the vesicular bilayer was not saturated with tretinoin, in the case of both multilamellar vesicles and unilamellar vesicles, indicating a possible modulation of drug permeation in the skin. $^{48}$

\section{Elastic Vesicles to Improve Skin Permeation}

The previously described studies confirmed that conventional liposomes could be useful for the administration of drugs owing to their biocompatible composition, but since they are not able to reach the deeper skin layers and consequently the site of the inflammation/infection caused by acne, the researchers suggested modifying the composition to improve the permeation of the loaded active compounds (Table 2). ${ }^{4-52}$ As reported by many studies in the literature, the deformability or elasticity of vesicles plays an important role in overcoming the stratum corneum barrier and thus enhancing the permeation of the loaded drug into the deeper skin layers. In general, we can assume that vesicles are considered deformable when they are able to cross intact the stratum corneum, deforming themselves and carrying active compounds through the skin (Figure 3). ${ }^{53-55}$ Ultradeformable vesicles and etho were the first vesicular carriers specifically defined as elastic and deformable nanosystems, thanks to the presence of an edge activator and ethanol in their respective structures. The innate deformability of certain topical nanosystems is due to the presence of cosurfactant in their structure, as well as the type of phospholipids (saturated or unsaturated) or specific solvent, which influence the ability of the carrier to reach the deeper skin layers to obtain dermal or transdermal delivery. ${ }^{30}$ Previous studies highlighted the interaction and accumulation of rhodamine-labeled ultradeformable vesicles within skin cell lines (Figure 4), thus showing a good cutaneous applicability of these carriers. ${ }^{56}$ Different types of deformable vesicles have been used to investigate their potential in topical acne treatment. Ultradeformable vesicles could squeeze through the stratum corneum and reach the deeper skin layers, as described by Cevc and Blume. ${ }^{49}$ Ultradeformable vesicles are made up of sodium cholate, deoxycholate, Span 80, Tween 80 and dipotassium glycyrrhizinate; these components act as an edge activator, destabilizing the lipid bilayer both of nanosystems and of the skin's structures. ${ }^{57,58}$

Vasanth et al, in 2020, proposed a gel enriched with vitamin $\mathrm{C}$ containing adapalene-loaded ultradeformable vesicles to treat acne. ${ }^{18}$ According to the authors, the combination therapy of adapalene and vitamin $\mathrm{C}$ could be helpful in avoiding the side effects of the conventional monotherapy with adapalene owing to the antioxidant and depigmenting activity of vitamin $\mathrm{C}$. The choice of ultradeformable vesicles for adapalene and vitamin $\mathrm{C}$ codelivery was found to be suitable, as the deformability property of ultradeformable vesicles seems to influence the release kinetics. In vitro release studies showed a sustained biphasic release of adapalene-loaded ultradeformable vesicles. The deformability of the carrier probably induces an initial accumulation of the drug on the stratum corneum, followed by a gradual release after the carrier diffusion through the skin. This biphasic release trend enabled a skin deposit of adapalene double that obtained from the compared Adiff aqueous gel (IPCA Laboratories, Maharashtra, India), the marketed formulation $\left(188.77 \mu \mathrm{g} \mathrm{cm}^{-2} \mathrm{~h}^{-1}\right.$ and $79.61 \mu \mathrm{g} \mathrm{cm}^{-2} \mathrm{~h}^{-1}$, respectively), confirming the strong and active interaction between ultradeformable vesicles and lipid structures of the skin. The accumulation of vitamin $\mathrm{C}$ was limited to the epidermis, where the aqueous content was very high, because of its hydrophilic nature. The obtained skin deposition of drug suggests that its transdermal permeation is limited, thus reducing systemic side effects. Therefore, the skin deposition of adapalene-loaded ultradeformable vesicles allows a lower concentration of drug to reach the therapeutic goal. Last but not least, the adapalene encapsulated into ultradeformable vesicles resulted in protection from exposure to UV radiation, and cutaneous side effects of inflammation and lesion counts were reduced. ${ }^{18}$

A multidrug formulation based on adapalene was prepared and evaluated by Jain et al. ${ }^{59}$ The retinoid was coencapsulated with benzoyl peroxide in a modified flexible liposomal gel and compared with the marketed Epiduo ${ }^{\circledR}$ (Galderma, Watford, UK), composed of the same active ingredients. The authors observed that, owing to the higher lipophilicity of the two drugs, they could not be coencapsulated in conventional liposomes, because they would destabilize the lipid bilayer of liposomes, modifying their structure, size and polydispersity index. In addition, the rigid liposomal structure did not allow the penetration of drugs into the deeper skin layers, as was necessary for acne treatment. The issue of co-delivery of adapalene and benzoyl peroxide has been overcome by the addition of Cetiol $\mathrm{B}^{\circledR}$ and Acconon C-44 EP/NF during preparation to increase the solubility of both drugs, and this modification created formulations with a higher drug loading. 
Table 2 Summary of the Main Features of Nanovesicles in Use or Under Development for Acne Treatment

\begin{tabular}{|c|c|c|c|c|}
\hline Nanocarriers & $\begin{array}{l}\text { Composition/ } \\
\text { Description }\end{array}$ & Advantages & Disadvantages & $\begin{array}{l}\text { Some } \\
\text { Delivered } \\
\text { Anti-Acne } \\
\text { Active } \\
\text { Ingredients }\end{array}$ \\
\hline Liposomes $^{24-26,28-30,34-38,40-43,50}$ & $\begin{array}{l}\text { Spherical vesicles, } \\
\text { characterized by } \\
\text { a phospholipid bilayer (made } \\
\text { of dipalmitoyl } \\
\text { phosphatidylcholine, } \\
\text { hydrogenated soya lecithin, } \\
\text { fatty alcohol polyglycol } \\
\text { ether, cholesterol, } \\
\text { dicetylphosphate) and an } \\
\text { aqueous core }\end{array}$ & $\begin{array}{l}\text { Controlled drug release; } \\
\text { decreased skin irritation; } \\
\text { reduced side effects of free } \\
\text { drug; formulation versatility; } \\
\text { increased drug solubilization; } \\
\text { drug protection from light } \\
\text { and oxygen }\end{array}$ & $\begin{array}{l}\text { Poor stability due to lipid } \\
\text { peroxidation and } \\
\text { accumulation in the upper } \\
\text { skin layers; limited } \\
\text { permeation through skin }\end{array}$ & $\begin{array}{l}\text { Clindamycin; } \\
\text { retinoic acid; } \\
\text { benzoyl } \\
\text { peroxide; tea } \\
\text { tree oil }\end{array}$ \\
\hline Niosomes ${ }^{22,44-48,50,51}$ & $\begin{array}{l}\text { Vesicles containing non-ionic } \\
\text { surfactant bilayer (such as } \\
\text { cetyl alcohol, decyl } \\
\text { glucoside, Brij, polysorbates, } \\
\text { spans, poloxamers, alkyl } \\
\text { polyglucoside surfactants) } \\
\text { enclosing an aqueous cavity }\end{array}$ & $\begin{array}{l}\text { Greater vesicle stability; } \\
\text { non-toxic nature and lower } \\
\text { cost than liposomes; } \\
\text { improved drug permeation } \\
\text { through the stratum } \\
\text { corneum and higher skin } \\
\text { retention }\end{array}$ & $\begin{array}{l}\text { Inability to reach the deeper } \\
\text { skin layers }\end{array}$ & $\begin{array}{l}\text { Retinoic acid; } \\
\text { terazotene }\end{array}$ \\
\hline Etho $^{30,50,52-55,69-72}$ & $\begin{array}{l}\text { Elastic nanosystems } \\
\text { containing phospholipids, } \\
\text { high amount of ethanol, and } \\
\text { water }\end{array}$ & $\begin{array}{l}\text { Excellent flexibility; ability to } \\
\text { passage through stratum } \\
\text { corneum; high loading } \\
\text { capacity for lipophilic drugs; } \\
\text { relatively simple and } \\
\text { inexpensive to manufacture }\end{array}$ & $\begin{array}{l}\text { Skin irritation due to high } \\
\text { concentration of alcohol } \\
\text { and poor skin penetration }\end{array}$ & Azelaic acid \\
\hline $\begin{array}{l}\text { Ultraderformable } \\
\text { vesicles }^{18,49,52,56-62,64--68}\end{array}$ & $\begin{array}{l}\text { Deformable vesicles due to } \\
\text { the presence of edge } \\
\text { activator (such as sodium } \\
\text { cholate, sodium } \\
\text { deoxycholate, Span } 80, \\
\text { Tween } 80 \text { and dipotassium } \\
\text { glycyrrhizinate) }\end{array}$ & $\begin{array}{l}\text { High deformability; ability to } \\
\text { destabilize skin lipid } \\
\text { organization; increased } \\
\text { permeation into the deeper } \\
\text { skin layers }\end{array}$ & $\begin{array}{l}\text { Mechanism of action is still } \\
\text { not clear; conflicting } \\
\text { information on their ability } \\
\text { to reach the systemic } \\
\text { circulation }\end{array}$ & $\begin{array}{l}\text { Adapalene; } \\
\text { benzoyl } \\
\text { peroxide; } \\
\text { retinoic acid; } \\
\text { photosensitizer }\end{array}$ \\
\hline LeciPlex ${ }^{31,73}$ & $\begin{array}{l}\text { Vesicular nanocarrier } \\
\text { containing a combination of } \\
\text { phospholipids and cationic } \\
\text { surfactants (such as } \\
\text { didodecyldimethyl } \\
\text { ammonium bromide, } \\
\text { cetyltrimethylammonium } \\
\text { bromide) }\end{array}$ & Enhanced skin deposition & $\begin{array}{l}\text { Few studies on human skin } \\
\text { have been performed }\end{array}$ & Azelaic acid \\
\hline Invasomes ${ }^{31,50,52,73}$ & $\begin{array}{l}\text { Flexible carriers made of } \\
\text { phosphatidylcholine, } \\
\text { terpenes (such as limonene, } \\
\text { cineole, fenchone, citral) } \\
\text { and ethanol }\end{array}$ & $\begin{array}{l}\text { Enhanced drug percutaneous } \\
\text { permeation, thus } \\
\text { guaranteeing faster activity }\end{array}$ & $\begin{array}{l}\text { Irritation and toxicity may } \\
\text { occur as a function of the } \\
\text { used penetration enhancers. } \\
\text { Mechanism of skin } \\
\text { permeation not completely } \\
\text { clear; few available studies }\end{array}$ & $\begin{array}{l}\text { Dapsone; } \\
\text { azelaic acid; } \\
\text { curcumin }\end{array}$ \\
\hline
\end{tabular}




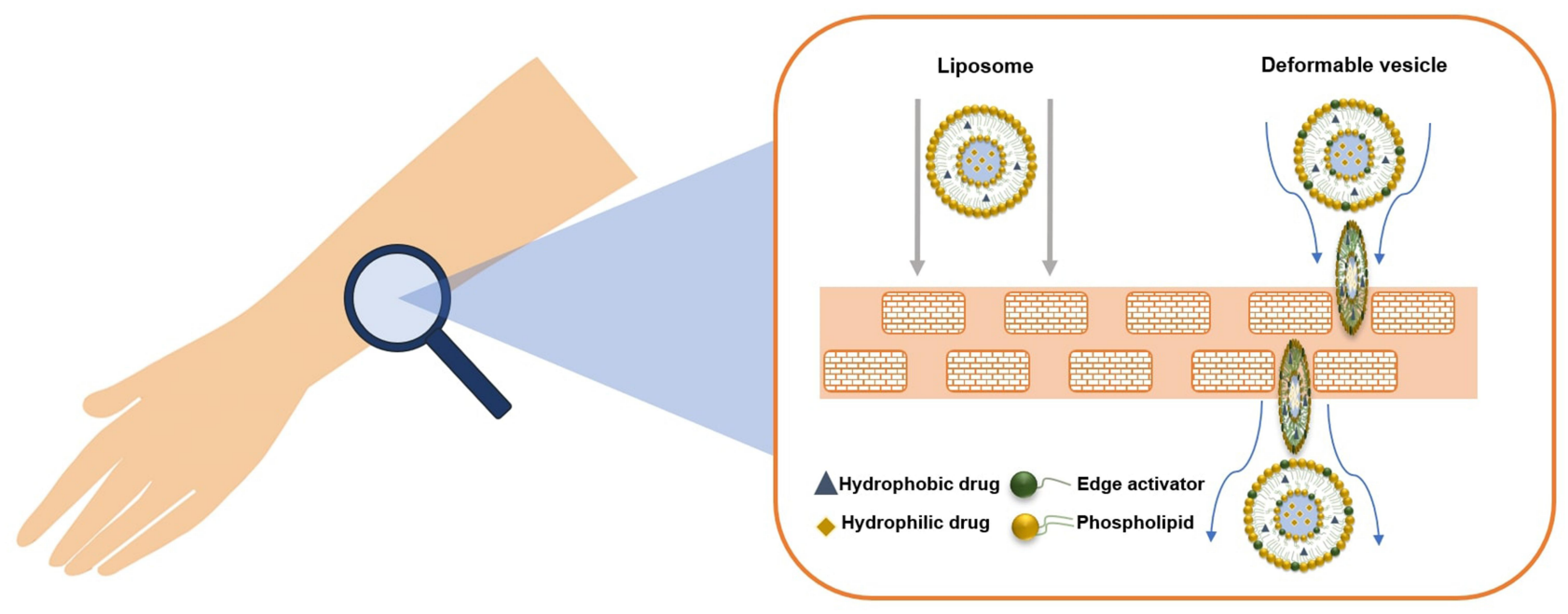

Figure 3 Topical treatment using liposomes or deformable vesicles. Both the carriers are able to deliver hydrophobic and hydrophilic compounds.

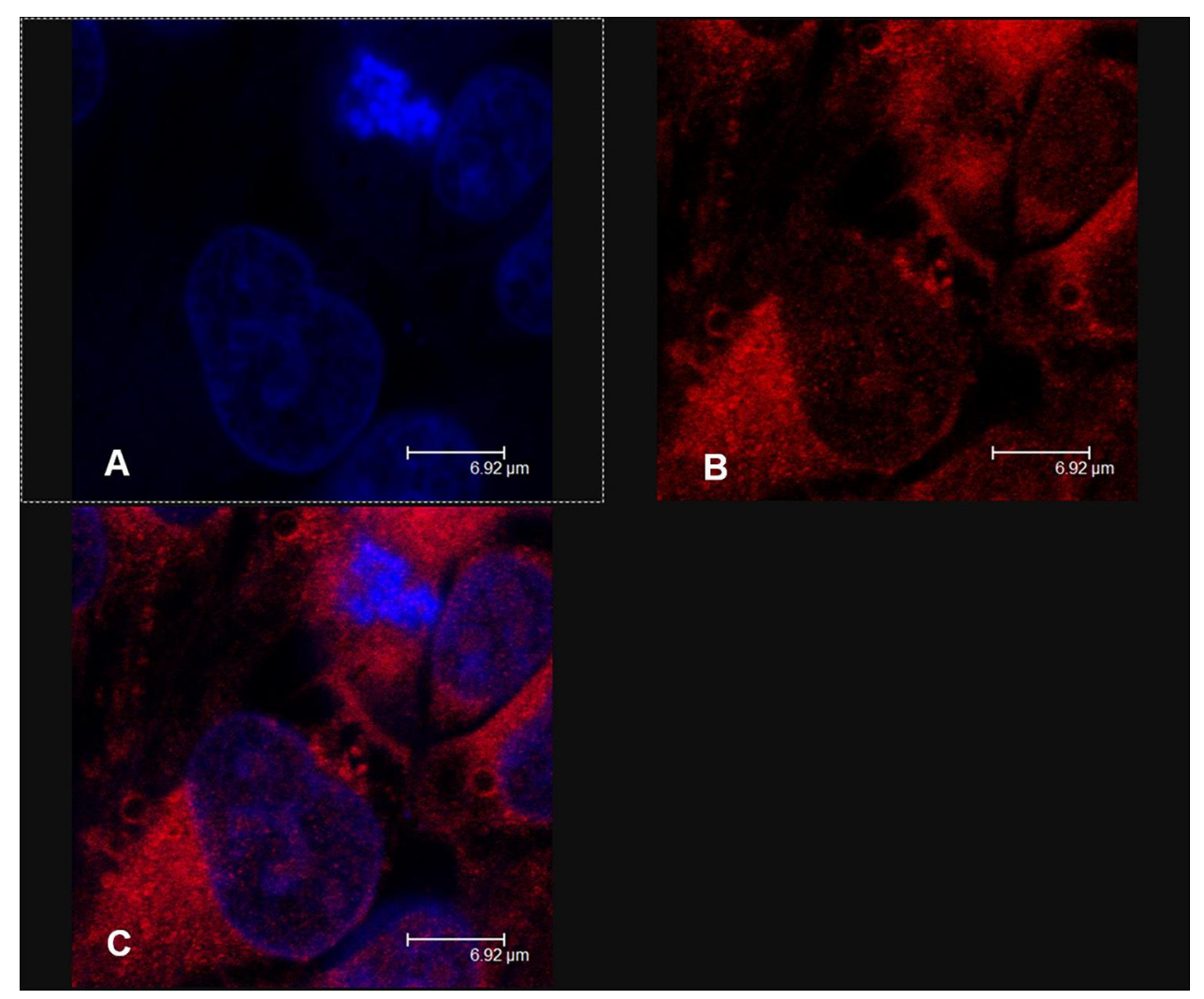

Figure 4 Confocal laser scanning micrographs of the interaction between ultradeformable vesicles labeled with rhodamine and Colo-38 cells using: (A) Hoechst filter and (B) TRITC filter; and (C) superimposition of figures. Reprinted with permission from Cosco D, Paolino D, Maiuolo J, et al. Ultradeformable liposomes as multidrug carrier of resveratrol and 5-fluorouracil for their topical delivery. Int J Pharm. 20I5;489(I-2):I-10. Copyright @ 2015 with permission from Elsevier Ltd. ${ }^{56}$

Moreover, the addition of the edge activator sodium deoxycholate (SDC), normally present in ultradeformable vesicle formulations, increased the deformability of the modified liposomes and improved their permeation into the deeper skin layers. ${ }^{59}$ The resulting formulation was very stable, also as a result of the negative surface charge conferred by SDC, which limits aggregating phenomena, and it exhibited a sustained release of drugs that was regulated in time (prolonged effect) and in the site of release (skin accumulation of drugs). ${ }^{60}$ The employed 
excipients conferred the desired permeating abilities, such as guaranteeing high skin bioavailability whilst avoiding the toxic effects related to systemic transport. In vivo and in vitro studies have shown that this formulation is safer and more effective than the commercial product. ${ }^{61}$

Ascenso et al demonstrated that tretinoin-loaded ultradeformable vesicles, made of phosphatidylcholine and Tween 80 , were able to enhance skin delivery, especially into the stratum corneum and epidermis, without causing skin irritation, which is the main side effect that occurs after the topical application of commercially available tretinoin. The authors did not perform follicular detection of the drug, but they studied its ability to permeate the skin. No detectable drug concentration was found in the receptor phase of Franz diffusion cells within 24 hours, suggesting that no transdermal delivery occurs within this time frame, probably owing to the lipophilic nature of tretinoin and its skin accumulation. ${ }^{62}$ These studies confirm that elastic vesicles are able to increase the permeation into the deeper skin layers without systemic delivery of the carried drugs.

Nanotechnology is often able to further improve the effectiveness of other topical treatments. This is the case, for example, with phototherapy. Photodynamic therapy has been proposed as an alternative treatment for acne disease, but it is unable to selectively act on microorganisms distinct from mammalian cells and it is also unable to act on microorganisms in the deeper skin layers owing to the lower permeability of photosensitizers. ${ }^{63}$ Trusting in the potential effectiveness of phototherapy, Park et al proposed a new strategy pairing the advantage of ultradeformable vesicles with the phototherapy concept. The authors presented a new formulation of ultradeformable vesicles made of a photosensitizer and polymerizable lipid conjugate, DSPE-PEG-Pheo A (1,2-distearoyl-sn-glycero -3-phosphoethanolamine-N-[amino(polyethylene glycol]2000-pheophorbide A), cholesterol and Tween 80 for selective delivery to the photosensitive $P$. acne lipase. Park et al proved that by including a photosensitizer in the transfersomal vesicle structure, its solubility and its skin penetration efficacy were increased; moreover, $P$. acne lipase-responsive photoactivity was better modulated, making the photosensitizer activity on the microorganism more specific, and reducing its side effects, such as oxidative stress and free radical production on the skin. Once again, the work confirmed that the deformability and permeability of ultradeformable vesicles are the consequence of their composition, and in this case they are consequent to the presence of PEG and Tween $80 .{ }^{64}$

Although the described studies have proven the efficacy of ultradeformable vesicles, their exact mechanism of skin permeation and the skin depth reached remain unclear to date. ${ }^{65}$

Some research groups reported the existence of "virtual channels" to justify the permeation of ultradeformable vesicles and also the reaching of the deeper skin layers. ${ }^{66,67}$ Many other authors have denied this theory, although the increase in skin permeation of the delivered drug using ultradeformable vesicles has been confirmed. ${ }^{57}$ A study conducted by El Maghraby et al showed that reaching deeper or less deep skin layers, or the possible crossing of the skin to reach the bloodstream, could depend on the shape, surface, elasticity or deformability of the vesicle, and therefore these factors were correlated to the components and the type of preparation chosen. ${ }^{68}$

Another class of topical drug delivery systems defined as deformable and elastic carriers is represented by etho (Figure 5). ${ }^{69,70}$ The elasticity of these systems is related to their chemical composition, and in particular to the high concentrations of ethanol that characterize their structure. This solvent is well known as a permeation enhancer, because it is able to induce a temporary disorganization of the lipid structure of the stratum corneum, but when

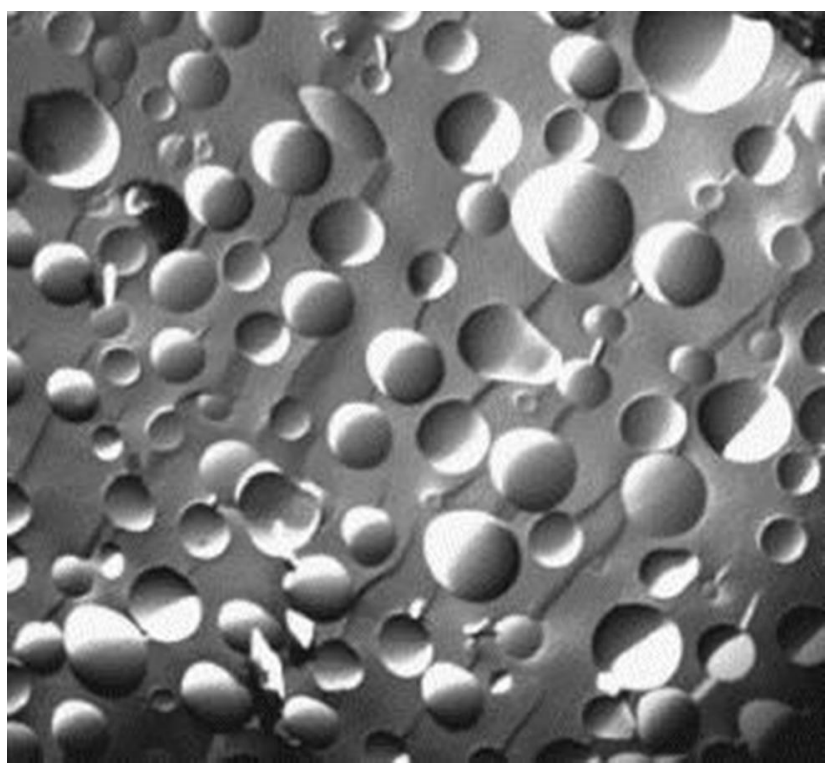

Figure 5 Representation of a generic ethosomal formulation using freeze-fracture electron microscopy. Reprinted with permission from Paolino D, Lucania G, Mardente D, Alhaique F, Fresta M. Ethosomes for skin delivery of ammonium glycyrrhizinate: In vitro percutaneous permeation through human skin and in vivo anti-inflammatory activity on human volunteers. J Control Release. 2005; I06(I-2):99-1 10. Copyright (C) 2005 with permission from Elsevier Ltd. ${ }^{70}$ 
added to a phospholipid mixture it localizes itself into the bilayer, conferring characteristics of elasticity and deformability, and consequently increased permeation of the loaded active ingredient across the skin. ${ }^{69}$ Despite the fact that etho is characterized by promising delivery properties, demonstrated by several research works for other skin diseases, very few studies have evaluated the potential of etho in acne treatment based on the most commonly used drugs. ${ }^{55,70,71}$

In particular, a 2019 study used etho to deliver azelaic acid and to take advantage of ethanol activity on lipid structures. ${ }^{72}$ In this case, the authors suggested that ethanol contained in ethosomal vesicles caused a disorganization of the bacterial membrane, changing the lipid composition, similarly to their effect on human skin. The changes in the bacterial membrane produced an increased permeation of the drug in the cytoplasmic level of $P$. acne, where azelaic acid exerts its pharmacological action. The azelaic acid-based etho, made up of 35\% $(w / w)$ ethanol and included in a cream formulation, was compared to the commercial Zelface ${ }^{\circledR}$ cream, and it showed better activity against $P$. acne; that is, the minimum bactericidal concentration $(\mathrm{MBC})$ values reported for the ethosomal and the marketed formulations were $250 \mu \mathrm{g} / \mathrm{mL}$ and $500 \mu \mathrm{g} /$ $\mathrm{mL}$, respectively. ${ }^{72}$

As already mentioned (Table 2), the composition plays a key role in determining the deformability and permeating abilities of nanosystems. Some research groups have investigated other nanosystems as potential flexible carriers. A new phospholipid vesicle, invasome, has been presented as a system able to improve the permeation through the skin, thus decreasing absorption into the systemic circulation. ${ }^{73}$ This innovative carrier is composed of phosphatidylcholine and terpenes that synergistically act with ethanol in disrupting the ordered structure of the stratum corneum to enhance the percutaneous permeation of the drug and to make phospholipid structures flexible. El-Nabarawi et al prepared dapsone-loaded invasomes for acne treatment, using different concentrations of various terpenes (limonene, cineole, fenchone and citral). They showed that the release of drug from invasomes was greater with increasing terpene concentrations, except in the case of limonene, the most lipophilic terpene used, which presented an opposite correlation. The authors found a 2.5-fold enhanced drug concentration into skin following the application of dapsone-loaded invasomes, compared to a generic dapsone solution. However, to date, the exact mechanism of permeation of these carriers through the skin is not completely clear and requires further investigation. In fact, only smaller and flexible vesicles seem to penetrate intact through the stratum corneum. ${ }^{74}$

Another study compared invasomes with two other systems (liposomes and LeciPlex, a cationic phospholipidbased vesicular system) for their ability to deliver drugs deep into the skin. Azelaic acid was encapsulated into the three proposed systems and in vitro studies were performed to investigate the antimicrobial activity against $P$. acne. Didodecyldimethyl ammonium bromide (DDAB) LeciPlex vesicles loaded with azelaic acid (concentrations above $10 \mathrm{M}$ ) showed the best efficacy against $P$. acne, followed by invasomes and cetyltrimethylammonium bromide (CTAB) LeciPlex, which presented almost the same activity. Further in vivo studies on rats revealed the opposite anti-acne efficacy scale; that is, invasomes seemed to be the best carrier, followed by liposomes and LeciPlex. When vesicles were analyzed using confocal laser scanning microscopy (CLSM), both of the cationic LeciPlex vesicles showed greater fluorescence into the hair follicle, but it is noteworthy that they also showed the slowest efficacy during in vitro studies. Moreover, during ex vivo studies on excised human skin, azelaic acid-loaded invasomes had the best penetration ability in different skin layers, compared with the other analyzed systems, probably owing to their greater deformability. The authors suggested that the lower penetration of drug from the LeciPlex systems may be due to the interaction of azelaic acid with the cationic surfactant of vesicles, which is strictly dependent on the different permeating ability of the surfactants employed during their preparation. In contrast, owing to their penetrating ability and releasing capacity, invasomes allow the drug to reach the inflammatory site and to produce a faster activity. ${ }^{31}$

Taking into account the analyzed vesicles, it seems clear that two main factors influence the efficacy of the treatment of acne disease: the ability to ensure suitable permeation of the active compound through the skin and the selectivity of the site of action, in order to enhance the skin absorption and localization of the administered drugs whilst avoiding toxicity.

\section{Conclusion}

Acne is a multifactorial disease related to inflammatory and non-inflammatory lesions. Because of the multifactorial pathogenesis of acne, the current therapies are not able to solve the pathology, but they simply lead to a reduction in clinical signs. The main limitations of the most 
commonly used anti-acne drugs (retinoids, antibiotics and other antimicrobial agents) are related to their side effects consequent to both systemic and topical conventional administration. In this scenario, the topical nanotechnologies could represent a valid approach to obtain a specific, effective and efficacious treatment by using lower doses of anti-acne drugs than conventional formulations, enhancing skin drug retention whilst avoiding toxicity. In this review, we have described several proposed nanosystems able to cross the stratum corneum and to deliver the $\operatorname{drug}(\mathrm{s})$ to the sites of action. In our opinion, all of the described nanosystems present notable characteristics when topically applied. Liposomes increase the amount of drug that permeates the stratum corneum compared with free form or conventional creams, lotions and solutions. Moreover, starting with liposomes, modification of their composition permits the production of new nanovesicles characterized by higher chemical stability, such as niosomes; higher deformability, such as etho, ultradeformable vesicles and invasomes; or higher penetrating ability, such as cationic carriers. This versatility of the composition of nanosystems could allow personalized therapy. The most suitable carrier can be chosen depending on the physicochemical characteristics and the site of action of the $\operatorname{drug}(s)$, the depth of the skin layers to be reached for acne treatment, and the need to deliver a single drug or a combination of drugs.

Moreover, the versatility of liposomes, niosomes and other flexible and deformable vesicles is confirmed by their stability when introduced in conventional formulations. The preparation of liposomal or transfersomal gels or creams for acne treatment combines the drug delivery abilities of nanosystems with the technological characteristics of the conventional formulation, such as spreadability, viscosity and ease of application, leading to the patients' compliance. Unfortunately, compared to the numerous scientific studies confirming the efficacy and safety of the described nanosystems in the treatment of acne, there are very few nanotechnological products currently on the market. This is probably because some aspects are still unclear, such as the skin permeation mechanism of ultradeformable vesicles or their localization in a specific skin layer. For this reason, the scientific research focuses on anti-acne treatments, trying to push the market to believe more strongly in the use of nanotechnologies. Suitable nanosystems for acne treatment have yet to be realized. In our opinion, the nanosystem must keep the good features of the described carriers, such as biocompatibility, good stability, controlled drug release and good therapeutic efficacy. However, it also has to guarantee specific targeting with good follicular bioavailability, since acne is an inflammatory disease involving the pilosebaceous follicles, and it needs to promote good retention in situ, thus avoiding reaching the deeper skin layers, which could lead to systemic side effects.

\section{Abbreviations}

P. acne, Propionibacterium acnes; PEG, polyethylene glycol; Pheo A, pheophorbide A; TEWL, transepidermal water loss.

\section{Acknowledgment}

The authors are very grateful to Dr Betty P. Udongo for the revision of the language of this manuscript.

\section{Disclosure}

The authors report no conflicts of interest in this work.

\section{References}

1. Purdy S, de Berker D. Acne vulgaris. BMJ Clin Evid. 2011;2011:1714.

2. Kim J-Y, Lee W-R, Kim K-H, et al. Effects of bee venom against propionibacterium acnes-induced inflammation in human keratinocytes and monocytes. Int $J$ Mol Med. 2015;35:1651-1656. doi: $10.3892 / \mathrm{ijmm} .2015 .2180$

3. Dréno B, Bettoli V, Araviiskaia E, Viera MS, Bouloc A. The influence of exposome on acne. JEADV. 2018;32(5):812-819.

4. Salman A, Kurt E, Topcuoglu V, Demircay Z. Social anxiety and quality of life in vitiligo and acne patients with facial involvement: a Cross-Sectional Controlled Study. Am J Clin Dermatol. 2016;17 (3):305-311. doi:10.1007/s40257-016-0172-x

5. Samuels DV, Rosenthal R, Lin R, Chaudhari S, Natsuaki MN. Acne vulgaris and risk of depression and anxiety: a meta-analytic review. $J$ Am Acad Dermatol. 2020;83(2):P532-P541. doi:10.1016/j. jaad.2020.02.040

6. Tripathi SV, Gustafson CJ, Huang KE, Feldman SR. Side effects of common acne treatment. Expert Opin Drug Saf. 2013;12(1):39-51. doi:10.1517/14740338.2013.740456

7. Zaenglein AL, Pathy AL, Schlosser BJ, et al. Guidelines of care for the management of acne vulgaris. J Am Acad Dermatol. 2016;74 (5):945-973.e33. doi:10.1016/j.jaad.2015.12.037

8. Gollnick H. Current concepts of the pathogenesis of acne implications for drug treatment. Drugs. 2003;63(15):1579-1596. doi:10.2165/00003495-200363150-00005

9. Akhavan A, Bershad S. Topical acne drugs: review of clinical properties, systemic exposure, and safety. Am J Clin Dermatol. 2003;4 (7):473-492. doi:10.2165/00128071-200304070-00004

10. Krautheim A, Gollnick HPM. Acne: topical treatment. Clin Dermatol. 2004;22(5):398-407. doi:10.1016/j.clindermatol.2004.03.009

11. Otlewska A, Baran W, Batycka-Baran A. Adverse events related to topical drug treatments for acne vulgaris. Expert Opin Drug Saf. 2020;19(4):513-521. doi:10.1080/14740338.2020.1757646

12. Valacchi G, Rimbach G, Saliou C, Weber SU, Packer L. Effect of benzoyl peroxide on antioxidant status, NF-kB activity and interleukin-1 $\alpha$ gene expression in human keratinocytes. Toxicology. 2001;165 (2-3):225-234. doi:10.1016/S0300-483X(01)00430-9 
13. Worret WI, Fluhr JW. Acne therapy with topical benzoyl peroxide, antibiotics and azelaic acid. JDDG. 2006;4(4):293-300. doi:10.1111/ j.1610-0387.2006.05931.x

14. Sagransky M, Yentzer BA, Feldman SR. Benzoyl peroxide: a review of its current use in the treatment of acne vulgaris. Expert Opin Pharmacother. 2009;10(15):2555-2562.

15. Schulte BC, Wu W, Rosen T. Azelaic acid: evidence-based update on mechanism of action and clinical application. $J$ Drugs Dermatol. 2015;14(9):964-968.

16. Hamilton FL, Car J, Lyons C, Car M, Layton A, Majeed A. Laser and other light therapies for the treatment of acne vulgaris: systematic review. Br J Dermatol. 2009;160(6):1273-1285. doi:10.1111/j.13652133.2009.09047.x

17. Gorzelanny C, Mess C, Schneider SW, Huck V, Brandner JM. Skin barriers in dermal drug delivery: which barriers have to be overcome and how can we measure them? Pharmaceutics. 2020;12(7):684. doi:10.3390/pharmaceutics12070684

18. Vasanth S, Dubey A, Ravi GS, et al. Development and investigation of vitamin C-enriched adapalene-loaded transfersome gel: a collegial approach for the treatment of acne vulgaris. AAPS PharmSciTech. 2020;21(2):61. doi:10.1208/s12249-019-1518-5

19. Molinaro R, Gagliardi A, Mancuso A, et al. Development and in vivo evaluation of multidrug ultradeformable vesicles for the treatment of skin inflammation. pharmaceutics. Pharmaceutics. 2019;11(12):644 doi:10.3390/pharmaceutics11120644

20. Liu Q, Das M, Liu Y, Huang L. Targeted drug delivery to melanoma. Adv Drug Deliv Rev. 2018;127:208-211. doi:10.1016/j. addr.2017.09.016

21. Latter G, Grice JE, Mohammed Y, Roberts MS, Benson HAE. Targeted topical delivery of retinoids in the management of acne vulgaris: current formulations and novel delivery systems. Pharmaceutics. 2019;11(10):490. doi:10.3390/pharmaceutics11100490

22. Cristiano MC, Froiio F, Mancuso A, et al. In vitro and in vivo trans-epidermal water loss evaluation following topical drug delivery systems application for pharmaceutical analysis. J Pharm Biomed. 2020;186:113295. doi:10.1016/j.jpba.2020.113295

23. Schmid M-H, Korting HC. Therapeutic progress with topical liposome drugs for skin disease. Adv Drug Deliv Rev. 1996;18 (3):335-342. doi:10.1016/0169-409X(95)00019-4

24. Honzak L, Sentjurc M. Development of liposome encapsulated clindamycin for treatment of acne vulgaris. Pflugers Arch. 2000;445 (Supp15):R44-R45.

25. Patel VB, Misra A, Marfatia YS. Topical liposomal gel of tretinoin for the treatment of acne: research and clinical implications. Pharm Dev Technol. 2000;5:455-464. doi:10.1081/PDT-100102029

26. Schäfer-Korting M, Korting HC, Ponce-Pöschl E. Liposomal tretinoin for uncomplicated acne vulgaris. Clin Investig. 1994;72:1086-1091. doi:10.1007/BF00577761

27. Lasic DD. Novel applications of liposomes. Trends Biotechnol. 1998;16(7):307-321. doi:10.1016/S0167-7799(98)01220-7

28. Skalko N, Cajkovac M, Jalenjack I. Liposomes with clindamycin hydrochloride in the therapy of acne vulgaris. Int J Pharm. 1992;85 (1-3):97-101. doi:10.1016/0378-5173(92)90138-R

29. Masini V, Bonte F, Meybeck A, Wepierre J. Cutaneous bioavailability in hairless rats of tretinoin in liposome or gel. J Pharm Sci. 1993;82 (1):17-21. doi:10.1002/jps.2600820104

30. Castro GA, Ferreira LA. Novel vesicular and particulate drug delivery systems for topical treatment of acne. Expert Opin Drug Deliv. 2008;5(6):665-679. doi:10.1517/17425247.5.6.665

31. Shah SM, Ashtikar M, Jain AS, et al. LeciPlex, invasomes, and liposomes: a skin penetration study. Int J Pharm. 2015;490(1-2):391-403. doi:10.1016/j.ijpharm.2015.05.042

32. Jung $\mathrm{S}$, Otberg $\mathrm{N}$, Thiede $\mathrm{G}$, et al. Innovative liposomes as a transfollicular drug delivery system: penetration into porcine hair follicles. J Invest Dermatol. 2006;126(8):1728-1732. doi:10.1038/sj. jid.5700323
33. Rahman SA, Abdelmalak NS, Badawi A, Elbayoumy T, Sabry N, El Ramly A. Tretinoin-based liposomal formulations: from lab to comparative clinical study in acne patients. Drug Deliv. 2016;23 (4):1184-1193. doi:10.3109/10717544.2015.1041578

34. Eroğlu İ, Aslan M, Yaman Ü, et al. Liposome-based combination therapy for acne treatment. J Liposome Res. 2019;30(3):263-273. doi:10.1080/08982104.2019.1630646

35. Patel VB, Misra A, Marfatia YS. Clinical assessment of the combination therapy with liposomal gels of tretinoin and benzoyl peroxide in acne. AAPS PharmSciTech. 2001;2(3):1-5. doi:10.1208/ pt0203_tn4

36. Fluhr JW, Barsom O, Gehring W, Gloor M. Antibacterial effi cacy of benzoyl peroxide in phospholipid liposomes. A vehicle-controlled, comparative study in patients with papulopustular acne. Dermatology. 1999;198:273-277. doi:10.1159/000018129

37. Musthaba SM, Baboota S, Ahmed S, Ahuja A, Ali J. Status of novel drug delivery technology for phytotherapeutics. Expert Opin Drug Deliv. 2009;6(6):625-637. doi:10.1517/17425240902980154

38. Bilia AR, Guccione C, Isacchi B, Righeschi C, Firenzuoli F, Bergonzi MC. Essential oils: new perspectives in human health and wellness. Evid Based Complement Alternat Med. 2014;2014:1-14.

39. Daud FS, Pande G, Joshi M, Pathak R, Wankhede S. A study of antibacterial effect of some selected essential oils and medicinal herbs against acne causing bacteria. IJPSI. 2013;2(1):27-34.

40. Valenti D, De Logu A, Loy G, et al. Liposome- incorporated santolina insularis essential oil: preparation, characterization, and in vitro antiviral activity. J Liposome Res. 2001;11(1):73-90. doi:10.1081/ LPR-100103171

41. Turina AV, Nolan MV, Zygadlo JA, Perillo MA. Natural terpenes: self-assembly and membrane partitioning. Biophys Chem. 2006;122:101-113. doi:10.1016/j.bpc.2006.02.007

42. Biju SS, Ahuja A, Khar RK. Tea tree oil concentration in follicular casts after topical delivery: determination by high-performance thin layer chromatography using a perfused bovine udder model. J Pharma Sci. 2005;94(2):240-245. doi:10.1002/jps.20250

43. Sherry M, Charcosset C, Fessi H, Greige-Gerges H. Essential oils: encapsulated in liposomes: a review. J Liposome Res. 2013;23 (4):268-275. doi:10.3109/08982104.2013.819888

44. Kazi KM, Mandal AS, Biswas N, et al. A future of targeted drug delivery systems. J Adv Pharm Technol Res. 2010;1(4):374-380. doi:10.4103/0110-5558.76435

45. Abdelkader H, Alani AWG, Alany RG. Recent advances in non-ionic surfactant vesicles (niosomes): self-assembly, fabrication, characterization, drug delivery applications and limitations. Drug Deliv. 2014;2(2):87-100. doi:10.3109/10717544.2013.838077

46. Moghassemi S, Hadjizadeh A. Nano-niosomes as nanoscale drug delivery systems: an illustrated review. $J$ Control Release. 2014;185:22-36. doi:10.1016/j.jconrel.2014.04.015

47. Choi MJ, Maibach HI. Liposomes and niosomes as topical drug delivery systems. Skin Pharmacol Phys. 2005;18(5):209-219. doi:10.1159/000086666

48. Manconi M, Sinico C, Valenti D, Lai F, Fadda AM. Niosomes as carriers for tretinoin: III. A study into the in vitro cutaneous delivery of vesicle-incorporated tretinoin. Int J Pharm. 2006;311(1-2):11-19. doi:10.1016/j.ijpharm.2005.11.045

49. Ceve G, Blume G. Lipid vesicles penetrate into intact skin owing to the transdermal osmotic gradients and hydration force. Biochim Biophys Acta. 1992;1104(1):226-232. doi:10.1016/0005-2736(92) 90154-E

50. Patel R, Prabhu P. Nanocarriers as versatile delivery systems for effective management of acne. Int J Pharm. 2020;579:119140. doi:10.1016/j.ijpharm.2020.119140

51. Aggarwal G, Nagpal M, Kaur G. Development and comparison of nanosponge and niosome based gel for the topical delivery of terazotene. Pharm Nanotechnol. 2016;4(3):213-228. doi:10.2174/ 2211738504666160804154213 
52. Roberts MS, Mohammed Y, Pastore MN, et al. Topical and cutaneous delivery using nanosystems. J Control Release. 2017;247:86-105. doi:10.1016/j.jconrel.2016.12.022

53. Honeywell-Nguyen PL, Bouwstra JA. The in vitro transport of pergolide from surfactant-based elastic vesicles through human skin: a suggested mechanism of action. J Control Release. 2003a;86 (1):145-156. doi:10.1016/S0168-3659(02)00415-7

54. Honeywell-Nguyen PL, Groenink HWW, de Graaff AM, Bouwstra JA. The in vivo transport of elastic vesicles into human skin: effects of occlusion, volume and duration of application. $J$ Control Release. 2003;90(2):243-255. doi:10.1016/S01683659(03)00202-5

55. Cristiano MC, Froiio F, Spaccapelo R, et al. Sulforaphane-loaded ultradeformable vesicles as a potential natural nanomedicine for the treatment of skin cancer diseases. Pharmaceutics. 2020;12(1):6. doi:10.3390/pharmaceutics12010006

56. Cosco D, Paolino D, Maiuolo J, et al. Ultradeformable liposomes as multidrug carrier of resveratrol and 5-fluorouracil for their topical delivery. Int $J$ Pharm. 2015;489(1-2):1-10. doi:10.1016/j. ijpharm.2015.04.056

57. Benson HAE. Transfersomes for transdermal drug delivery. Expert Opin Drug Deliv. 2006;3(6):727-737. doi:10.1517/17425247.3.6.727

58. Bouwstra JA, De Graaff A, Groenink W, Honeywell L. Elastic vesicles: interaction with human skin and drug transport. Cell Mol Biol Lett. 2002;7(2):222-223.

59. Jain A, Jain P, Umamaheshwari RB, Jain NK. Transfersomes-a novel vesicular carrier for enhanced transdermal delivery: development, characterization, and performance evaluation. Drug Dev Ind Pharm. 2003;29(9):1013-1026. doi:10.1081/DDC-120025458

60. Das S, Ng WK, Tan RBH. Are nanostructured lipid carriers (NLCs) better than solid lipid nanoparticles (SLNs): development, characterizations and comparative evaluations of clotrimazole-loaded SLNs and NLCs? Eur J Pharm Sci. 2012;47(1):139-151. doi:10.1016/j. ejps.2012.05.010

61. Jain S, Kale DP, Swami R, Katiyar SS. Codelivery of benzoyl peroxide \& adapalene using modified liposomal gel for improved acne therapy. Nanomedicine. 2018;13(12):1481-1493. doi:10.2217/nnm2018-0002

62. Ascenso A, Salgado A, Euletério C, et al. In vitro and in vivo topical delivery studies of tretinoin-loaded ultradeformable vesicles. Eur J Parm Biopharm. 2014;88(1):48-55. doi:10.1016/j.ejpb.2014.05.002

63. Hamblin MR, Hasan T. Photodynamic therapy: a new antimicrobial approach to infectious disease? Photochem Photobiol Sci. 2004;3 (5):436-450. doi:10.1039/b311900a
64. Park H, Lee J, Jeong S, et al. Lipase-sensitive transfersomes based on photosensitizer/polymerizable lipid conjugate for selective antimicrobial photodynamic therapy of acne. Adv Healthc Mater. 2016;5 (24):3139-3147. doi:10.1002/adhm.201600815

65. Rai S, Pandey V, Rai G. Transfersomes as versatile and flexible nano-vesicular carriers in skin cancer therapy: the state of the art. Nano Rev Exp. 2017;8(1):1325708. doi:10.1080/20022727.2017.1325708

66. Guo J, Ping Q, Sun G, Jiao C. Lecithin vesicular carriers for transdermal delivery of cyclosporin A. Int $J$ Pharm. 2000;194 (2):201-207. doi:10.1016/S0378-5173(99)00361-0

67. Cevc G, Schätzlein A, Richardsen H. Ultradeformable lipid vesicles can penetrate the skin and other semi-permeable barriers unfragmented. Evidence from double label CLSM experiments and direct size measurements. Biochim Biophys Acta. 2002;1564(1):21-30. doi:10.1016/S0005-2736(02)00401-7

68. El Maghraby GM, Williams AC, Barry BW. Can drug-bearing liposomes penetrate intact skin? J Pharm Pharmacol. 2006;58 (4):415-429. doi:10.1211/jpp.58.4.0001

69. Touitou E, Dayan N, Bergelson L, Godin B, Eliaz M. Ethosomes novel vesicular carriers for enhanced delivery: characterization and skin penetration properties. J Control Release. 2000;65(3):403-418. doi:10.1016/S0168-3659(99)00222-9

70. Paolino D, Lucania G, Mardente D, Alhaique F, Fresta M. Ethosomes for skin delivery of ammonium glycyrrhizinate: in vitro percutaneous permeation through human skin and in vivo anti-inflammatory activity on human volunteers. J Control Release. 2005;106(1-2):99-110. doi:10.1016/j.jconrel.2005.04.007

71. Marto J, Vitor C, Guerreiro A, et al. Ethosomes for enhanced skin delivery of griseofulvin. Colloids Surf B. 2016;146:616-623. doi:10.1016/j.colsurfb.2016.07.021

72. Apriani EF, Rosana Y, Iskandarsyah I. Formulation, characterization, and in vitro testing of azelaic acid ethosome-based cream against propionibacterium acnes for the treatment of acne. J Adv Pharm Technol Res. 2019;10(2):75-80. doi:10.4103/japtr.JAPTR_289_18

73. Babaie S, Del Bakhshayesh AR, Ha JW, Hamishehkar H, Kim KH. Invasome: a novel nanocarrier for transdermal drug delivery. Nanomaterials. 2020;10(2):341. doi:10.3390/nano10020341

74. El-Nabarawi MA, Shamma RN, Farouk F, Nasralla SM. Dapsoneloaded invasomes as a potential treatment of acne: preparation, characterization, and in vivo skin deposition assay. AAPS PharmSciTech. 2018;19(5):2174-2184. doi:10.1208/s12249-018-1025-0
International Journal of Nanomedicine

\section{Publish your work in this journal}

The International Journal of Nanomedicine is an international, peerreviewed journal focusing on the application of nanotechnology in diagnostics, therapeutics, and drug delivery systems throughout the biomedical field. This journal is indexed on PubMed Central, MedLine, CAS, SciSearch ${ }^{\mathbb{}}$, Current Contents ${ }^{\mathbb{R}} /$ Clinical Medicine, $^{-}$
Journal Citation Reports/Science Edition, EMBase, Scopus and the Elsevier Bibliographic databases. The manuscript management system is completely online and includes a very quick and fair peer-review system, which is all easy to use. Visit http://www.dovepress.com/ testimonials.php to read real quotes from published authors. 